\title{
Leite humano processado em bancos de leite para o recém-nascido de baixo peso: análise nutricional e proposta de um novo complemento ${ }^{1}$
}

\author{
Eliana Aparecida Fagundes Queiroz Bortolozo, ${ }^{2}$ Emiliana Borges Tiboni ${ }^{3}$ \\ e Lys Mary Bileski Cândido 4
}

Como citar: Bortolozo EAFQ, Tiboni EB, Cândido LMB. Leite humano processado em bancos de leite para o recémnascido de baixo peso: análise nutricional e proposta de um novo complemento. Rev Panam Salud Publica. 2004;16(3):199-205.

RESUMO Objetivo. Analisar a composição de macro e micronutrientes minerais no leite humano coletado e processado em bancos de leite e desenvolver um complemento que, incorporado a esse leite, satisfaça as exigências nutricionais específicas do recém-nascido de baixo peso.

Método. Para a determinação de macronutrientes, 46 amostras de leite pasteurizado obtidas de dois bancos de leite foram analisadas em triplicata: 26 amostras de leite maduro, 10 de colostro e 10 de leite de mães de bebês prematuros. Em 30 dessas amostras (10 de cada tipo) foram determinados também os micronutrientes. Após a determinação dos macro e micronutrientes, desenvolveu-se um complemento de simples preparo, composto de hidrolisado protéico e minerais quelatos. Resultados. A composição variou tanto entre os diferentes tipos de leite quanto entre doadoras do mesmo tipo de leite. Os valores de micro e macronutrientes foram inferiores às necessidades dos recém-nascidos de baixo peso. A composição média observada (e desvio-padrão) para leite maduro, colostro e leite de mães de prematuros foi: lipídios $(\mathrm{g} / 100 \mathrm{~mL}), 2,56( \pm 0,8), 2,48( \pm 0,91), 2,48$ $( \pm 0,76)$; lactose $(\mathrm{g} / 100 \mathrm{~mL}), 8,6( \pm 0,93), 7,05( \pm 0,92), 6,56( \pm 1,41)$; proteínas $(\mathrm{g} / 100 \mathrm{~mL}), 1,07$ $( \pm 0,22), 1,71( \pm 0,29), 1,72( \pm 0,4)$; calorias (kcal/100 mL), 61,67 ( $\pm 8,92), 57,36( \pm 8,37), 55,44$ $( \pm 8,00)$; cálcio $(\mathrm{mg} / 100 \mathrm{~mL}), 17,88( \pm 5,56), 22,75( \pm 10,24), 22,03( \pm 9,39)$; magnésio $(\mathrm{mg} /$ $100 \mathrm{~mL}), 2,15( \pm 0,39), 2,64( \pm 0,67), 2,16( \pm 0,26) ;$ potássio $(\mathrm{mg} / 100 \mathrm{~mL}), 35,53( \pm 7,54), 43,75$ $( \pm 14,32), 44,37( \pm 12,83) ;$ sódio $(m g / 100 m L), 16,27( \pm 5,92), 43,36( \pm 11,34), 37,98( \pm 11,34)$; zinco $(\mathrm{mg} / 100 \mathrm{~mL}), 0,46( \pm 0,26), 0,75( \pm 0,25), 0,72( \pm 0,26)$; fósforo $(\mathrm{mg} / 100 \mathrm{~mL}), 9,98$ $( \pm 1,72), 9,31( \pm 4,30), 8,47( \pm 2,43)$. Com a adição do complemento, os níveis de proteína e dos minerais estudados passaram a se enquadrar nas recomendações para recém-nascidos de baixo peso. Conclusão. Com base nos resultados obtidos é justificável a complementação do leite armazenado em bancos para uso por recém-nascidos de baixo peso. O complemento desenvolvido mostrou viabilidade operacional, não interferindo na qualidade microbiológica do leite humano.

Palavras-chave Nutrição infantil.

Estudo financiado com recursos do Departamento de Nutrição da Universidade Federal do Paraná (UFPR)

2 Centro Federal de Educação Tecnológica do Paraná (CFET), Unidade Ponta Grossa. Enviar correspondência para esta autora no seguinte endereço: Rua Euzébio da Mota 361, CEP 84051530, Ponta Grossa, PR, Brasil. E-mail: bortolozopg@uol.com. br/bortolozo@pg.cefetpr.br
3 Universidade Federal do Paraná (UFPR), Centro de Produção e Processamento de Alimentos (CEPPA), Departamento de Nutrição, Programa de Pósgraduação em Ciências Farmacêuticas, Curitiba (PR), Brasil.

4 UFPR, Departamento de Nutrição.
O leite materno é reconhecido como o alimento mais adequado para recémnascidos, servindo como referência para estabelecer os requerimentos nutricionais nessa faixa etária. A Organização Mundial da Saúde (OMS) (1) re- 
comenda amamentação exclusiva por 4 a 6 meses e complementada até 2 anos ou mais. Nos Estados Unidos, a American Academy of Pediatrics (AAP) recomenda o aleitamento ao seio no $1^{\circ}$ ano de vida do recém-nascido a termo e reconhece os benefícios do leite humano no manejo de lactentes prematuros (2).

Há controvérsias sobre qual seria a composição ótima do leite para recémnascidos de baixo peso. Estudos clínicos em berçários mostraram uma diminuição na ocorrência de infecções em lactentes de baixo peso alimentados com leite humano. Avaliando-se prematuros hospitalizados (3), comprovou-se a menor incidência de enterocolite necrotizante naqueles alimentados, exclusiva ou parcialmente, com leite humano, em relação aos bebês alimentados com fórmulas. Apesar de apresentarem uma curva de crescimento deficiente, os prematuros alimentados com leite humano apresentaram vantagens no desenvolvimento psicomotor aos 18 meses de idade $(4,5)$.

Alguns estudos discutem a viabilidade do leite humano para alimentação de prematuros, especialmente em relação aos níveis de proteínas e minerais $(5,6)$. No caso do leite humano processado em bancos de leite, a composição de macro e micronutrientes pode ser inadequada para recémnascidos de baixo peso, seja porque as necessidades desses nutrientes são maiores nesse grupo, seja em função de perdas associadas à coleta, armazenagem e procedimentos da alimentação $(2,5,7)$. Outros estudos apontam considerável diferença na composição do leite de diferentes estágios de lactação $(8,9)$. Há evidências de que o leite de mães de prematuros é diferente daquele das mães de bebês que nasceram a termo, confirmando necessidades diferenciadas de nutrientes para recém-nascidos de baixo peso (10). Ainda assim, em função de sua composição e custo, o leite humano estocado em bancos de leite é a alternativa mais segura e menos dispendiosa no tratamento dietético dos recém-nascidos de baixo peso, prematuros ou não, impossibilitados de serem amamentados. Para assegurar, entretanto, a qualidade desse leite, é fundamental conhecer o seu perfil nutricional e microbiológico.

Assim, o objetivo deste estudo foi analisar a composição nutricional do leite humano de dois bancos de leite e verificar sua adequação para alimentar recém-nascidos de baixo peso, bem como desenvolver um complemento para ajustar esse leite às necessidades dos recém-nascidos prematuros.

\section{MATERIAIS E MÉTODOS}

As atividades referentes à pesquisa com leite humano e sua manipulação foram aprovadas pelo Comitê de Ética em Pesquisas em Seres Humanos do Hospital de Clínicas da Universidade Federal do Paraná (HC/UFPR). Foram selecionadas 46 amostras de $100 \mathrm{~mL}$ de três tipos de leite: 26 amostras de leite maduro, 10 de colostro e 10 amostras de leite de mães de prematuros, com 36 semanas ou menos. O leite havia sido pasteurizado e estocado nos bancos de leite do HC/UFPR e do Município de Ponta Grossa. As amostras foram analisadas em triplicata no laboratório de pós-graduação do Departamento de Nutrição/UFPR.

\section{Avaliação da composição do leite humano}

O conteúdo de lipídeos totais foi analisado pelo método de butirômetro de Gerber. O conteúdo de proteínas foi determinado pelo método de Kjedahl, empregando-se o fator 6,38 para conversão de nitrogênio em proteínas totais (11). A lactose foi determinada pelo método de Folin Wu (12). Para o cálculo do valor calórico total foi utilizado o somatório dos valores calóricos médios referentes a proteína (4 kcal/g), lactose (4 kcal/g) e lipídeos (9 kcal/g). Cálcio, zinco, potássio, sódio e magnésio foram avaliados por espectrometria de absorção atômica (13) no Centro de Pesquisa e Processamento de Alimentos da UFPR, e o fósforo, de acordo com o procedimento descrito por Graaner et al. (14).

Para o estudo estatístico das análises de macro e micronutrientes minerais utilizaram-se instrumentos de estatística descritiva, de forma a detalhar o comportamento quanto a assimetria, dispersão e localização. Para comparar a concentração de nutrientes nos três tipos de leite foi utilizada a análise de variância (ANOVA) nos casos onde os pressupostos básicos não foram violados, e o teste de Kruskal-Wallis (estatística não paramétrica) quando um ou mais pressupostos não foram satisfeitos. Para os cálculos empregaram-se os programas Statgraphics Plus 2.1 e Statistica 6.0.

\section{Desenvolvimento do complemento}

A formulação incluiu, como fonte protéica, hidrolisado de proteína de concentrado de soro de leite, comercialmente denominado ALATAL 821, cedido pela empresa New Zeland Milk Products. Como fonte de minerais foram utilizados os minerais aminoácidos quelatos cedidos pelo Laboratório Albion, na forma comercial Cálcio Taste Free ${ }^{\circledR}$ (13\% Ca) e Magnésio Taste Free ${ }^{\circledR}(8 \%$ $\mathrm{Mg}$ ). Para avaliar a manutenção da qualidade microbiológica do leite humano depois da adição do complemento, realizaram-se análises microbiológicas (em duplicata) do leite pasteurizado nos bancos e do leite pasteurizado enriquecido com complemento. Essas análises, realizadas no Laboratório de Microbiologia do Centro Federal de Educação Tecnológica do Paraná em Ponta Grossa, avaliaram os padrões microbiológicos descritos na Resolução n 12 de 2001 da Secretaria Nacional de Vigilância Sanitária (Ministério da Saúde do Brasil), específicos para leite materno de bancos de leite humano. Com base no regulamento técnico, foram analisados: o número de microrganismos aeróbios mesófilos viáveis por $\mathrm{mL}$; o número de coliformes por $\mathrm{mL}$ a $35{ }^{\circ} \mathrm{C}$; o número de estafilococos coagulase-positivos por $\mathrm{mL}$ e o número de Salmonella $s p$ em $25 \mathrm{~mL}$ (15).

A fim de avaliar o tempo de validade do complemento desenvolvido, usou-se o Aqualab CX-2 para analisar a atividade de água (Aw). Foram preparadas cinco amostras de $10 \mathrm{~g}$ do complemento, em diferentes datas, com intervalo de zero a 50 dias. 
TABELA 1. Composição em termos de calorias ${ }^{a}$ do leite humano de dois bancos de leite no Estado do Paraná, Brasil, 2002

\begin{tabular}{|c|c|c|c|c|c|c|c|c|c|c|}
\hline Tipo de leite & $n$ & Média & Mediana & Total & Mínimo & Máximo & $\begin{array}{c}\text { Primeiro } \\
\text { quartil }\end{array}$ & $\begin{array}{c}\text { Terceiro } \\
\text { quartil }\end{array}$ & Variância & $\begin{array}{l}\text { Desvio- } \\
\text { padrão }\end{array}$ \\
\hline Maduro & 26 & 61,67 & 61,05 & 1603,39 & 45,46 & 82,45 & 55,06 & 67,09 & 79,5015 & 8,9164 \\
\hline Colostro & 10 & 57,36 & 56,19 & 573,57 & 43,15 & 73,77 & 53,24 & 58,85 & 70,0613 & 8,3703 \\
\hline Mãe de prematuro & 10 & 55,44 & 55,38 & 554,44 & 45,31 & 72,25 & 48,53 & 56,99 & 63,9891 & 7,9993 \\
\hline
\end{tabular}

a Todos os resultados apresentados como g em $100 \mathrm{~mL}$ de leite $(\mathrm{g} / 100 \mathrm{~mL})$.

\section{RESULTADOS}

Os resultados da análise dos micro e macronutrientes minerais nas amostras de leite humano são apresentados nas tabelas de 1 a 4 . Ocorreu variação significativa nos itens proteína e lactose para o leite maduro em relação ao colostro e ao leite de mães de recém-nascidos prematuros $(P<0,005)$. Para gordura e calorias, as concentrações não apresentaram variação significativa $(P>0,005)$. Os coeficientes de variação entre doadoras para lactose, proteína e lipídios foram, respectivamente, $21,83,20,80$ e $32,35 \%$, mostrando, portanto, maior variação no teor de lipídios.

Quanto aos micronutrientes, houve variação significativa para o mineral sódio $(P<0,005)$, que no leite maduro foi inferior aos demais. Para o potássio não houve variação significativa $(P>$
0,005). Como os valores das concentrações de cálcio, magnésio, zinco e fósforo não atenderam os pressupostos da análise de variância paramétrica, foram analisados com o teste de Kruskal-Wallis. Quanto ao magnésio, o colostro apresentou concentração significativamente superior aos outros leites; para o zinco, o leite maduro apresentou média significativamente inferior aos demais. Os coeficientes de variação entre doadoras para cálcio, magnésio, potássio, sódio, zinco e fósforo foram, respectivamente: 39,57; 18,$64 ; 27,63$; 32,55; 40,05; e 30,6\%, mostrando, assim, variação mais acentuada no teor de cálcio e zinco.

\section{Complemento}

O complemento proposto tem baixo custo e é de simples preparo, limitado à pesagem dos ingredientes (em pó), sua homogeneização num vidro ou béquer estéril, com bastão estéril, e envasamento em recipiente apropriado. A partir das análises dos macro e micronutrientes nas amostras de leite humano, constatou-se que os itens proteína e minerais (exceto o zinco) eram os que estavam mais aquém das recomendações para recém-nascidos de baixo peso. A proteína de soro de leite utilizada como base neste complemento contém alto valor nutricional e, sendo o tratamento enzimático um processo sensível e cuidadosamente monitorado, os aminoácidos essenciais permanecem intactos e a proteína conserva seu valor nutricional. O produto escolhido é recomendado para fórmulas infantis com redução de alergenicidade, fácil absorção e baixo teor de lactose. Segundo as informações do fabricante, o hidrolisado ALATAL 821, pelo baixo

TABELA 2. Concentração de macronutrientes no leite humano de dois bancos de leite no Estado do Paraná, Brasil, 2002

\begin{tabular}{|c|c|c|c|c|c|c|c|c|c|c|}
\hline Variável $(\mathrm{g} / 100 \mathrm{~mL})$ & $n$ & Média & Mediana & Total & Mínimo & Máximo & $\begin{array}{l}\text { Primeiro } \\
\text { quartil }\end{array}$ & $\begin{array}{l}\text { Terceiro } \\
\text { quartil }\end{array}$ & Variância & $\begin{array}{l}\text { Desvio- } \\
\text { padrão }\end{array}$ \\
\hline \multicolumn{11}{|l|}{ Lactose } \\
\hline Leite maduro & 26 & 8,60 & 8,63 & 223,5 & 6,11 & 10,18 & 8,15 & 9,22 & 0,8656 & 0,9304 \\
\hline Colostro & 10 & 7,05 & 7,18 & 70,52 & 4,93 & 8,04 & 6,65 & 7,82 & 0,8510 & 0,9225 \\
\hline Leite de mãe & & & & & & & & & & \\
\hline $\begin{array}{l}\text { de prematuro } \\
\text { Proteínas }\end{array}$ & 10 & 6,56 & 6,81 & 65,59 & 3,86 & 9,00 & 5,79 & 7,18 & 1,9840 & 1,4086 \\
\hline Leite maduro & 26 & 1,07 & 1,03 & 27,82 & 0,73 & 1,54 & 0,87 & 1,17 & 0,0502 & 0,2240 \\
\hline Colostro & 10 & 1,71 & 1,75 & 17,14 & 1,28 & 2,13 & 1,44 & 1,95 & 0,0854 & 0,2922 \\
\hline $\begin{array}{l}\text { de prematuro } \\
\text { Lipídios }\end{array}$ & 10 & 1,72 & 1,55 & 17,21 & 1,33 & 2,48 & 1,39 & 1,88 & 0,1647 & 0,4059 \\
\hline Leite maduro & 26 & 2,56 & 2,29 & 66,48 & 1,07 & 4,40 & 2,03 & 3,17 & 0,6355 & 0,7972 \\
\hline Colostro & 10 & 2,48 & 2,40 & 24,76 & 1,03 & 4,00 & 1,80 & 3,33 & 0,8208 & 0,9060 \\
\hline Leite de mãe & & & & & & & & & & \\
\hline de prematuro & 10 & 2,48 & 2,69 & 24,81 & 1,00 & 3,37 & 2,00 & 3,20 & 0,5725 & 0,7567 \\
\hline
\end{tabular}


TABELA 3. Concentração de micronutrientes minerais no leite humano de dois bancos de leite no Estado do Paraná, Brasil, 2002

\begin{tabular}{|c|c|c|c|c|c|c|c|c|c|c|}
\hline Variável (mg/L) & $n$ & Média & Mediana & Total & Mínimo & Máximo & $\begin{array}{l}\text { Primeiro } \\
\text { quartil }\end{array}$ & $\begin{array}{l}\text { Terceiro } \\
\text { quartil }\end{array}$ & Variância & $\begin{array}{l}\text { Desvio- } \\
\text { padrão }\end{array}$ \\
\hline \multicolumn{11}{|l|}{ Cálcio } \\
\hline Leite maduro & 10 & 178,79 & 159,17 & 1787,86 & 130,29 & 327,03 & 154,45 & 192,45 & 3090,60 & 55,59 \\
\hline $\begin{array}{l}\text { Colostro } \\
\text { Leite de mãe }\end{array}$ & 10 & 227,52 & 202,34 & 2 275,22 & 115,55 & 385,66 & 138,74 & 340,74 & 10488,40 & 102,41 \\
\hline $\begin{array}{l}\text { de prematuro } \\
\text { Magnésio }\end{array}$ & 10 & 220,03 & 194,83 & 2200,32 & 120,38 & 436,06 & 149,95 & 278,08 & 8828,89 & 93,96 \\
\hline Leite maduro & 10 & 21,49 & 21,34 & 214,78 & 14,49 & 26,36 & 18,98 & 25,17 & 15,5682 & 3,9457 \\
\hline $\begin{array}{l}\text { Colostro } \\
\text { Leite de mãe }\end{array}$ & 10 & 26,37 & 24,52 & 263,69 & 22,47 & 45,39 & 23,58 & 25,20 & 45,5337 & 6,7478 \\
\hline $\begin{array}{l}\text { de prematuro } \\
\text { Potássio }\end{array}$ & 10 & 21,56 & 22,12 & 215,63 & 16,56 & 24,52 & 20,30 & 23,53 & 6,6741 & 2,5834 \\
\hline Leite maduro & 10 & 355,24 & 348,23 & 3552,40 & 241,98 & 511,10 & 291,70 & 403,24 & 5702,12 & 75,5124 \\
\hline $\begin{array}{l}\text { Colostro } \\
\text { Leite de mãe }\end{array}$ & 10 & 437,49 & 449,86 & 4374,89 & 229,49 & 625,56 & 290,74 & 544,53 & 20496,70 & 143,167 \\
\hline $\begin{array}{l}\text { de prematuro } \\
\text { Sódio }\end{array}$ & 10 & 443,67 & 426,78 & 4436,70 & 229,44 & 648,09 & 386,46 & 541,11 & 16453,00 & 128,269 \\
\hline Leite maduro & 10 & 162,72 & 133,54 & 1627,23 & 90,64 & 291,92 & 129,66 & 202,67 & 3504,95 & 59,202 \\
\hline $\begin{array}{l}\text { Colostro } \\
\text { Leite de mãe }\end{array}$ & 10 & 433,61 & 419,07 & 4336,08 & 307,65 & 673,60 & 345,83 & 500,20 & 12856,50 & 113,38 \\
\hline de prematuro & 10 & 379,72 & 406,75 & 3797,24 & 145,96 & 560,95 & 285,02 & 471,91 & 17791,70 & 133,38 \\
\hline
\end{tabular}

peso molecular e baixo resíduo de beta lactoglobulina, pode ser indicado como ingrediente hipoalergênico.

A figura 1 compara os nove aminoácidos essenciais encontrados no leite humano conforme a descrição feita por Wit (16) e no hidrolisado presente no complemento. As diferenças mais significativas se referem à concentração de leucina, lisina e treonina, superiores no hidrolisado. Considerandose, porém, que o complemento não significará decisivamente o perfil de aminoácidos do leite humano enriquecido, essas diferenças podem não re- presentar prejuízo ao seu perfil biológico, diferentemente do que ocorre com o uso exclusivo de fórmulas à base de leite bovino.

$\mathrm{O}$ enriquecimento requer $3,2 \mathrm{~g}$ de complemento para $100 \mathrm{~mL}$ do leite pasteurizado, podendo-se, para tanto, utilizar balança ou colher-medida padronizada. A concentração dos ingredientes (ou a medida) poderia ser alterada em função das particularidades do lactente. A presente formulação foi calculada em função dos resultados deste estudo. Levou-se em conta, também, a concentração de minerais de cada mistura e sua biodisponibilidade (informada pelo fabricante).

A tabela 5 apresenta a composição nutricional básica do complemento comparada à do leite humano não suplementado, as necessidades nutricionais do recém-nascido de baixo peso e a composição do leite suplementado (17, 18). Com a adição do complemento, os níveis de proteína e dos minerais estudados passaram a se enquadrar nas recomendações para recém-nascidos de baixo peso. Recomenda-se padronizar as concentrações de gordura em $3 \mathrm{~g}$, através da triagem pelo método do cre-

TABELA 4. Concentração de zinco e fósforo no leite humano de dois bancos de leite no Estado do Paraná, Brasil, 2002

\begin{tabular}{|c|c|c|c|c|c|c|c|c|c|c|}
\hline Variável (mg/L) & $n$ & Média & Mediana & Total & Mínimo & Máximo & $\begin{array}{l}\text { Primeiro } \\
\text { quartil }\end{array}$ & $\begin{array}{c}\text { Terceiro } \\
\text { quartil }\end{array}$ & Variância & $\begin{array}{l}\text { Desvio- } \\
\text { padrão }\end{array}$ \\
\hline Leite maduro & 10 & 4,56 & 4,41 & 45,64 & 1,75 & 8,08 & 2,48 & 5,81 & 5,1326 & 2,2655 \\
\hline Colostro & 10 & 7,46 & 7,70 & 74,58 & 4,45 & 11,15 & 5,00 & 9,16 & 6,4362 & 2,5370 \\
\hline $\begin{array}{l}\text { Leite de mãe } \\
\text { de prematuro } \\
\text { Fósforo }\end{array}$ & 10 & 7,16 & 7,45 & 71,59 & 3,44 & 11,02 & 4,65 & 9,22 & 6,8242 & 2,6123 \\
\hline Leite maduro & 10 & 99,75 & 96,40 & 997,46 & 64,23 & 119,52 & 90,52 & 117,48 & 293,656 & 17,1364 \\
\hline $\begin{array}{l}\text { Colostro } \\
\text { Leite de mãe }\end{array}$ & 10 & 93,12 & 92,18 & 931,16 & 47,78 & 198,80 & 61,06 & 105,61 & 1850,62 & 43,0188 \\
\hline de prematuro & 10 & 84,69 & 75,50 & 846,88 & 58,80 & 134,99 & 67,32 & 102,14 & 587,83 & 24,2452 \\
\hline
\end{tabular}


matócrito (19), e a utilização de uma mistura de diversos leites, com diferentes teores de gordura.

O resultado das análises microbiológicas demonstrou que a rotina da produção e adição do complemento ao leite é segura, não interferindo na qualidade do leite já pasteurizado. O resultado final das análises revelou $<1$ $\mathrm{UFC} / \mathrm{mL}$ de aeróbios mesófilos viáveis, $<1 \mathrm{UFC} / \mathrm{mL}$ de coliformes a $25^{\circ} \mathrm{C},<10$ UFC/mL de Staphylococcus coagulasepositivos e ausência de Salmonella sp em $25 \mathrm{~mL}$. A figura 2 apresenta a atividade de água em função do tempo de armazenamento (em temperatura média de $20{ }^{\circ} \mathrm{C}$ ) do complemento.

\section{DISCUSSÃO}

Os resultados do presente estudo estiveram de acordo com dados publicados anteriormente em relação ao teor lipídico, levemente superior no leite maduro (9), em relação à lactose, cuja concentração foi mais baixa no leite de mães de prematuros (19), e em relação à proteína, cuja concentração foi maior no colostro e no leite de mães de prematuros $(5,9,10)$. Ainda quanto aos lipídeos, embora os diferentes leites não tenham apresentado variação significativa, ela se fez representativa entre doadoras do mesmo tipo de leite. Esse fato é justificável pelas características individuais de cada doadora, pelas diferentes idades de lactação e pelo período da mamada em que foi coletado o leite (5).

Nenhum dos tipos de leite analisados apresentou valores próximos às recomendações para recém-nascidos de baixo peso. Estudos anteriores (5, 20, 21) já mostravam que o leite humano maduro pode não atender às necessidades nutricionais desse grupo específico. Uma exceção foi o zinco, que apresentou valores na faixa recomendada de $0,5 \mathrm{mg} / \mathrm{dL}$ (22).

Em geral, a concentração de nutrientes no colostro foi ligeiramente superior à concentração no leite maduro e no leite de mães de recém-nascidos prematuros (com exceção do fósforo). Contudo, a disponibilidade do colostro é limitada no banco de leite, tor-
FIGURA 1. Diferenças na composição dos aminoácidos essenciais ${ }^{\mathrm{a}}$ entre o leite humano e o hidrolisado ALATAL

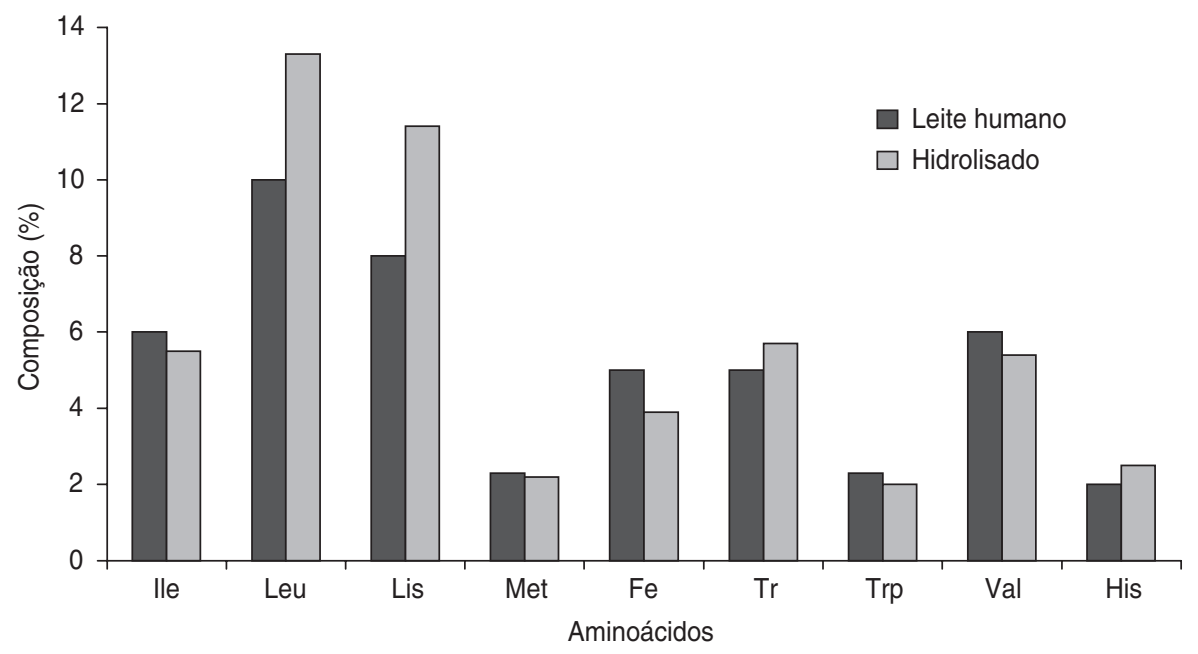

${ }^{a}$ Conforme Wit (16). nando inviável sua utilização em maior escala. O leite de mães de recém-nascidos prematuros apresentou valores mais elevados de $\mathrm{Ca}, \mathrm{K}, \mathrm{Na}$ e $\mathrm{Zn}$ em relação ao leite maduro. Porém, como acontece com o colostro, é pequena nos bancos de leite a disponibilidade de leite de mães de recém-nascidos prematuros, utilizado prioritariamente para filhos das próprias doadoras.

Todos os resultados deste estudo sugerem que o leite humano processado em bancos pode se beneficiar do enriquecimento com alguns nutrientes para adaptá-lo às necessidades específicas do recém-nascido de baixo peso, fato este que vem ao encontro de outros trabalhos $(5,20)$. Segundo Schanler (21), o uso de fortificante de leite humano possibilita um adequado crescimento ao recém-nascido de baixo peso, assim como assegura a retenção de nutrientes e índices bioquímicos positivos, quando comparado ao leite humano não fortificado. Comparado,
TABELA 5. Perfil nutricional de complemento para leite humano em bancos de leite

\begin{tabular}{|c|c|c|c|c|}
\hline $\begin{array}{c}\text { Nutriente } \\
\text { (em } 100 \mathrm{~mL} \text { ) }\end{array}$ & $\begin{array}{l}\text { Composição do } \\
\text { leite humano }\end{array}$ & Necessidade/dL ${ }^{b}$ & $\begin{array}{l}\text { Composição do } \\
\text { complemento }^{c}\end{array}$ & $\begin{array}{c}\text { Composição } \\
\text { complemento + leite } \\
\text { humano }\end{array}$ \\
\hline Calorias (Kcal) & 61,7 & 85 a 112 & 6,4 & $72,1^{d}$ \\
\hline Proteínas (g) & 1,1 & 2,5 a 3,0 & 1,6 & 2,67 \\
\hline Carboidratos (g) & 8,6 & 6,25 a 12,9 & 0,001 & 8,6 \\
\hline Lipídios (g) & 2,6 & 3,2 a 5,6 & - & $3,0^{\mathrm{e}}$ \\
\hline Cálcio (mg) & 17,87 & 120 a 200 & 94 & 120 \\
\hline Fósforo (mg) & 9,74 & 64 a 102 & 54,36 & 64 \\
\hline Magnésio (mg) & 2,47 & 4,1 a 8,1 & 2,53 & 5,0 \\
\hline Sódio (mg) & 17,27 & 22,5 a 75 & 10,8 & 28,27 \\
\hline Potássio (mg) & 35,52 & 80 a 113 & 46,11 & 81,63 \\
\hline Zinco (mg) & 0,46 & 0,47 a 0,55 & - & 0,46 \\
\hline
\end{tabular}

a Composição média do leite humano segundo resultados do presente estudo.

${ }^{b}$ Com base em recomendações internacionais $(17,18)$.

c Composição do complemento a partir do uso de $3,2 \mathrm{~g}$ para enriquecer $100 \mathrm{~mL}$ de leite humano.

d Valor calórico referente a no mínimo $3 \mathrm{~g}$ de gordura.

e Valor mínimo de gordura baseado na classificação do crematócrito. 
FIGURA 2. Atividade de água do complemento em diferentes tempos de preparo

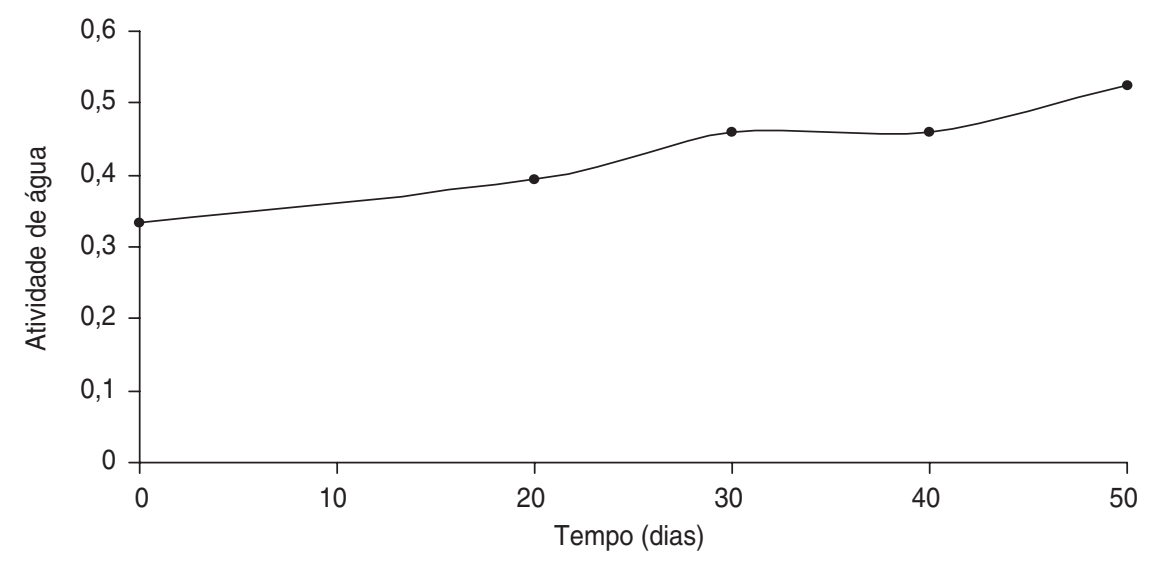

ainda, a fórmulas pré-termo, o leite humano fortificado pode também prover o lactente de significativa defesa contra infecções. Vale ressaltar que a fortificação do leite humano deve ser considerada apenas para os casos de recém-nascidos de baixo peso.

No item gordura, optou-se por uma metodologia de padronização do leite humano com níveis mínimos de 3 $\mathrm{g} / 100 \mathrm{~mL}$ como parte da rotina do banco de leite, tornando-se possível minimizar as flutuações dos nutrientes. Uma triagem destes leites para posterior mistura ao complemento resultaria num produto ideal quanto aos níveis de gordura, de uso seguro, sem custo adicional.

O valor calórico não sofreu acréscimo suficiente para atingir os padrões recomendados. Observando-se como padrão mínimo para a concentração de gordura a taxa de $3 \mathrm{~g} / 100 \mathrm{~mL}$, o valor mínimo de calorias passou de 61,7 para $72,1 \mathrm{kcal} \%$. Com a metodologia sugerida, espera-se menor oscilação nos níveis médios de calorias e gordura, fato importante detectado neste estudo. Ademais, a melhor digestibilidade da gordura do leite humano pode assegurar melhor eficiência do leite enriquecido, mesmo com valores calóricos abaixo dos patamares recomendados. A proporção entre cálcio e fósforo manteve-se dentro dos padrões do leite humano, em torno de 2:1. A adição de zinco fez-se desnecessária.

O custo do complemento foi considerado satisfatório, representando apenas $40 \%$ do custo de um complemento similar disponível no mercado. A suplementação do leite pode ser realizada nos lactários dos hospitais vinculados diretamente aos bancos de leite, mediante prescrição médica. Não se observou aumento do volume do leite quando o complemento em pó foi adicionado. Sua dispersão no líquido foi adequada. A dispersão do complemento mostrou-se ainda melhor após o aquecimento do leite à temperatura de $36{ }^{\circ} \mathrm{C}$. Comparando-se o leite pasteurizado normalmente oferecido no banco de leite ao leite pasteurizado adicionado de complemento, os dados demonstraram tratar-se de uma rotina segura, sem interferência na qualidade do leite já pasteurizado, fato este confirmado pelos resultados das análises microbiológicas.

A determinação da atividade da água em função do tempo de armazenamento fornece informações sobre a estabilidade do produto. O hidrolisado, matéria-prima base do complemento, é higroscópico, qualidade que poderia causar alterações no produto armazenado. Considerando este aspecto, assim como o fato de que o complemento é destinado a uma clientela de risco, não seria recomendável armazená-lo por mais de 20 ou 30 dias. Uma comprovação mais eficaz do tempo de prateleira do complemento requer avaliação em períodos superiores aos 50 dias em que se desenvolveu o estudo.

Em resumo, nossos resultados indicam que o leite humano processado em bancos de leite e destinado aos recémnascidos de baixo peso pode ter sua qualidade melhorada mediante enriquecimento com alguns nutrientes. Também foi constatada a viabilidade operacional do complemento proposto. Novos estudos de comparação do uso do complemento com grupo de controle poderão contribuir para confirmar os presentes resultados.

\section{REFERÊNCIAS}

1. WHO Working Group on Infant Growth. An evaluation of infant growth: the use and interpretation of anthropometry in infants. Bull World Health Organ. 1995;73(2):167-174. Disponível em: http://whqlibdoc.who.int/ bulletin/1995/Vol73-No2/bulletin_1995_ 73(2)_165-174.pdf. Acessado em junho de 2004.

2. American Academy of Pediatrics. Breastfeeding and the use of human milk. Pediatrics. 1997;100(6):1035-1039.
3. Lucas A, Fewtrell MS, Morley R. Randomized outcome trial of human milk fortification and developmental outcome in preterm infants. Am Clin Nutr. 1996;64(1):142-151.

4. Lucas A, Gore SM, Cole TJ, Banford MF. Multicentre trial on feeding low birth weight infants: effects of diet on early growth. Arch Dis Child. 1984;59(9):722-730.

5. Schanler RJ. Suitability of human milk for the low-birthweight infant. Clin Perinatol. 1995; 22(2):207-222.
6. Kuschel CA, Harding JE. Protein supplementation of human milk for promoting growth in preterm infants (Cochrane Review). Em: The Cochrane Library 4. Oxford: Update Software; 2001.

7. Greer FR, McCormick A. Improved bone mineralization and growth in premature infants fed fortified own mother's milk. J Pediatr. 1988;112(9):961-969.

8. Gross SJ, David RJ, Bauman L, Tomarelli RM. Nutritional composition of milk produced by 
mothers delivering preterm. J Pediatr. 1980; 96(4):641-644.

9. Lawrence PB. Breast milk. Best source of nutrition for term and preterm infants. Pediatr Clin North Am. 1994;41(5):925-941.

10. Dawodu AH, Osibanjo O, Damole IO. Nutrient composition of milk produced by mothers of preterm infants in Nigeria. East Afr Med J. 1990;67(7):873-377.

11. Instituto Adolfo Lutz. Normas analíticas do Instituto Adolfo Lutz: métodos químicos e físicos para análises de alimentos. $3^{\mathrm{a}}$ ed. São Paulo: Instituto Adolfo Lutz; 1985.

12. Triebold HO, Aurand LW. Food composition and analysis. New York: D. Van Nostrand Company; 1963.

13. Association of Official Analytical Chemists. Official methods of the Association of Official Analytical Chemists. $17^{\mathrm{a}}$ ed. Arlington, VA: AOAC; 2000.

14. Graaner CSF, Meira DR, Mucciolo P. Determinação de teor de fósforo em produtos cárneos. Rev Inst Adolfo Lutz. 1975;35/36:55-62.
15. International Commission on Microbiological Specifications for Foods (ICMSF). Microorganisms in foods 2: sampling for microbiological analysis: principles and specific applications. $2^{\mathrm{a}}$ ed. Toronto: University of Toronto Press; 1986. Disponível em: http://www. foodscience.afisc.csiro.au/icmsf/book2.htm. Acessado em junho de 2004.

16. Wit JN. Nutritional and functional characteristics of whey proteins in food products. J Dairy Sci. 1998;81(3):597-608

17. Nutrition and feeding of preterm infants. Committee on Nutrition of the Preterm Infant, European Society of Paediatric Gastroenterology and Nutrition. Acta Paediatr Scand Suppl. 1987;336:1-14.

18. Nutrition Committee, Canadian Pediatric Society. Nutrient needs and feeding of premature infants. Canadian Med Association J. 1985;52(11):1765-1785.

19. Lucas A, Gibbs JAH, Lyster RLJ, Baum JD. Crematrocrit: simple clinical technique for estimating fat concentration and energy value of human milk. Br Med J. 1978;1(6119):10181020.

20. American Academy of Pediatrics (AAP). Committee on nutritional needs of low birth weight. Pediatrics. 1985;75(6):976-986.

21. Schanler RJ. The use of human milk for premature infants. Pediatr Clin North Am. 2001 48(1):207-219.

22. Ferris AM, Dotts MA, Clark RM, Ezrin M, Jensen RG. Macronutrients in human milk at 2, 12, and 16 weeks postpartum. J Am Diet Assoc. 1988;88(6):694-697.

Manuscrito recebido em 4 de abril de 2003. Aceito em versão revisada em 26 de março de 2004
ABSTRACT

\section{Milk from human milk banks for low birthweight newborns: nutritional contents and supplementation}

Objective. To determine the macronutrient and micronutrient contents of human milk from milk banks as well as to develop a supplement for addition to this milk that could satisfy the specific nutritional requirements of low birthweight newborns.

Method. For the determination of macronutrients, 46 samples of pasteurized milk obtained from two milk banks were analyzed in triplicate: 26 samples of mature milk, 10 samples of foremilk and 10 samples of milk from mothers of preterm babies. Thirty of these samples (10 of each type of milk) were also analyzed for their micronutrient content. Following the determination of macronutrients and micronutrients, an easyto-prepare supplement was developed. The supplement was made from protein hydrolysate powder and chelate minerals.

Results. The nutritional content varied both among the different types of milk and among the donors of the same type of milk. The levels of macronutrients and micronutrients were below the requirements for low birthweight newborns. The mean composition (and standard deviation) observed for mature milk, foremilk, and preterm milk, respectively, was as follows: fats $(\mathrm{g} / 100 \mathrm{~mL}), 2.56( \pm 0.8), 2.48( \pm 0.91)$ 2.48 ( \pm 0.76); lactose $(\mathrm{g} / 100 \mathrm{~mL}), 8.6( \pm 0.93), 7.05( \pm 0.92), 6.56( \pm 1.41)$; protein $(\mathrm{g} /$ $100 \mathrm{~mL}), 1.07( \pm 0.22), 1.71( \pm 0.29), 1.72( \pm 0.4)$; calories $(\mathrm{kcal} / 100 \mathrm{~mL}), 61.67( \pm 8.92)$, $57.36( \pm 8.37), 55.44( \pm 8.00)$; calcium $(\mathrm{mg} / 100 \mathrm{~mL}), 17.88( \pm 5.56), 22.75( \pm 10.24), 22.03$ $( \pm 9.39)$; magnesium $(\mathrm{mg} / 100 \mathrm{~mL}), 2.15( \pm 0.39), 2.64( \pm 0.67), 2.16( \pm 0.26) ;$ potassium $(\mathrm{mg} / 100 \mathrm{~mL}), 35.53( \pm 7.54), 43.75( \pm 14.32), 44.37( \pm 12.83) ;$ sodium $(\mathrm{mg} / 100 \mathrm{~mL})$ 16.27 ( \pm 5.92$), 43.36$ ( \pm 11.34$), 37.98( \pm 11.34) ;$ zinc $(\mathrm{mg} / 100 \mathrm{~mL}), 0.46( \pm 0.26), 0.75$ $( \pm 0.25), 0.72( \pm 0.26) ;$ and phosphorus $(\mathrm{mg} / 100 \mathrm{~mL}), 9.98( \pm 1.72), 9.31( \pm 4.30), 8.47$ $( \pm 2.43)$. After the addition of the supplement, the protein and mineral contents reached the levels recommended for low birthweight newborns.

Conclusion. Based on our results obtained, the supplementation of human milk from milk banks is warranted for use with low birthweight newborns. The proposed supplement was shown to be practical and safe, and it did not interfere with the microbiological quality of human milk. 